\title{
Universal eye health in Odisha, India, Sunetra. Report \# I. Program planning
}

This article was published in the following Dove Press journal: Clinical Ophthalmology

\author{
Taraprasad Das ${ }^{1,2}$ \\ Sabyasachi Pattanayak ${ }^{1,3}$ \\ On behalf of the Odisha \\ Universal Eye Health \\ Empowered Committee \\ 'Odisha Universal Eye Health \\ Program, Hyderabad, India; ${ }^{2}$ Srimati \\ Kanuri Shantamma Center for \\ Vitreoretinal Diseases, LV Prasad \\ Eye Institute, Hyderabad, India; \\ ${ }^{3}$ Department of Ophthalmology, \\ Capital Hospital, Bhubaneswar, India
}

Purpose: To describe the program planning of Sunetra (Healthy Eyes), the universal eye health coverage in the Indian state Odisha.

Methods: The Indian state of Odisha launched the universal eye health coverage in October 2017. This is the first Indian state to officially respond to the World Health Organization's Global Action Plan.

Results: The Government of Odisha pledged INR 6,820 million (US\$ 100 million approximately) spread over 5 years. Each third of the pledged money is allocated for immediate direct benefit, building the infrastructure and human resources, and creating a digital eye health platform for uniform documentation and policy planning.

Conclusion: It is hoped that at the end of 5 years, by 2022, the state will attain the goals prescribed in the Global Action Plan in eye care.

Keywords: universal eye health, Odisha, India

\section{Introduction}

In adopting the resolution on the "universal eye health, the Global Action Plan 2014-2019" in the 66th World Health Assembly (66.4, 2013), the World Health Organization (WHO) urged the member states to "strengthen the national efforts to prevent avoidable blindness, provide universal and equitable service, and allocate the required budget for effective implementation of the program." A strong and equitable eye health system is based on three important pillars: 1) collection of evidence to measure the disease burden and causes, 2) development of human resource with training in comprehensive eye care, and 3) provision of comprehensive eye care to all. In order to achieve these, the WHO suggested that the governments 1) make adequate provisions covering curative, promotive, preventive, and rehabilitative measures for major causes of visual impairment and blindness; 2) provide access to everyone irrespective of economic status, ethnicity, gender, place of habitat, and disability status; 3) work toward integration of eye health with national health system; and finally 4) ensure equity of service such as to not prevent access for the poorest.

India designed the blindness prevention program in $1976 .{ }^{2}$ It was the first country to recognize blindness and visual impairment as an important health priority. For a long time, this program had been cataract-centric with little focus on universal eye care system. ${ }^{3}$ India has performed well in improving the cataract surgical rate $(5,136 / \text { million population in 2016 })^{2}$ and cataract surgical coverage, though it is not uniformly distributed across the country. ${ }^{4,5}$ India constituted a high-level expert group on universal health coverage in 2011 with a mandate to developing a framework for providing easily accessible and affordable health care to all defined under the universal
Correspondence: Taraprasad Das Srimati Kanuri Shantamma Center for Vitreoretinal Diseases, L V Prasad Eye Institute, Road \# 2, Banjara Hills, Hyderabad 500 034, India Email tpd@lvpei.org (c) (1) (5) 2018 Das and Pattanayak. This work is published and licensed by Dove Medical Press Limited. The full terms of this license are available at https://www.dovepress.com/terms.php (c) ${ }_{\mathrm{BY}} \mathrm{NC}$ and incorporate the Creative Commons Attribution - Non Commercial (unported, v3.0) License (http://creativecommons.org/licenses/by-nc/3.0/). By accessing the work you hereby accept the Terms. Non-commercial uses of the work are permitted without any further permission from Dove Medical Press Limited, provided the work is properly attributed. For permission for commercial use of this work, please see paragraphs 4.2 and 5 of our Terms (https://www.dovepress.com/terms.php). 
health coverage. ${ }^{6}$ Despite constituting the National Health Mission $^{7}$ and the existing tier system of health delivery, the universal health coverage in India is grossly inadequate. The reasons include lack of gap analysis and failure to address them, inadequate manpower and unequal distribution of trained people in rural and remote areas, poor quality of care that does not build confidence in the consumers, and lack of firm political will. ${ }^{8}$

Odisha, one of the 29 states of India (Figure 1), has lower eye care indices such as in cataract surgical rate $3,149 /$ million population in 2016 as against the India average of 5,136/million population. Comprehensive scientifically designed all-age population survey of blindness and visual impairment has never been done in this state. Recognizing these facts, the state leadership launched the universal eye health program on World Sight Day, October 12, 2017. Named, Sunetra (Healthy Eyes), the government pledged INR 6,820 million (US\$ 100 million approximately) for the program spread over 5 years. The bold message was "Eye Care for All by 2022."'9

The basis of the program is to reinforce progressive eye care universalism by the following actions: assess the magnitude of blindness by a scientifically designed all-age population-based study, raise skilled manpower by appropriate health personnel training, teach modern eye care techniques and technology to ophthalmologists-in-training and in-practice, digitalize the eye health delivery system for effective monitoring and big data analysis, create an integrated system of primary and secondary eye care, the village

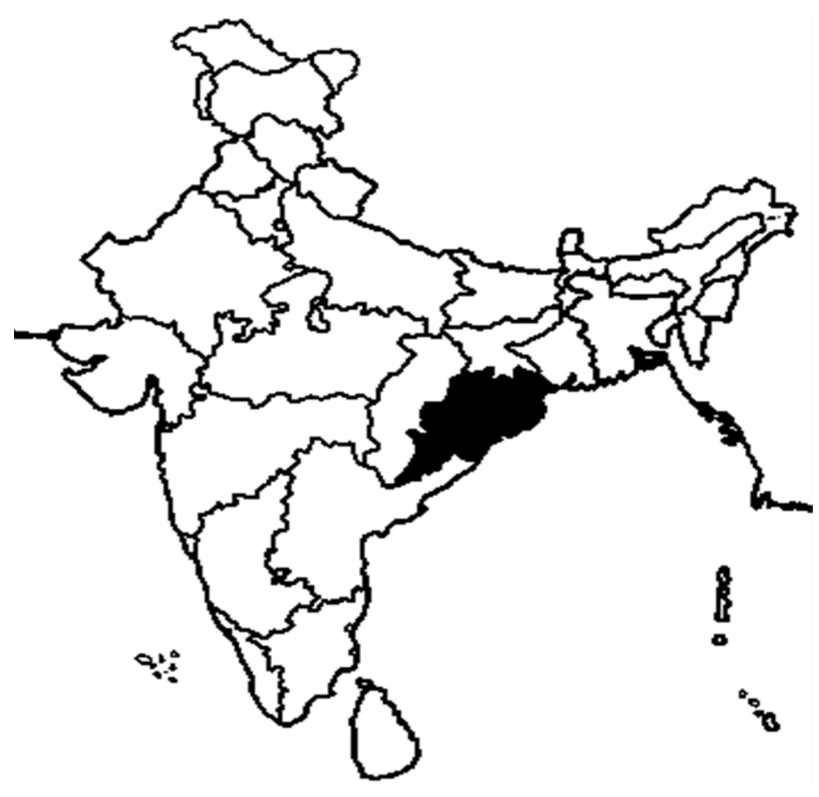

Figure I Odisha (dark shaded) state in India. vision complex, and proper referral system. The program also includes establishing a center to reskill all eye health personnel, a health policy and system research center with special focus on eye health.

\section{Methods}

The Department of Health and Family Welfare, Government of Odisha, constituted an empowered committee to design the universal eye health system and oversee its implementation. The committee made a few broad strategic decisions as follows: 1) assessment of magnitude of blindness and visual impairment by an all-age population-based study; 2) use already developed tool for gap analysis of both resources and performances at district level; 3) strengthen and empower the existing pyramidal health care model, 4) capacity building with appropriate training and placement of trained eye health personnel; 5) future ready for big data analysis starting with digital acquisition of all eye health data; 6) focused care for children; 7) creating a center for skilling and planning; and finally 8) bring synergy between the public and private eye health providers.

\section{Results}

The Sunetra plans to conduct a population-based study the Odisha Eye Disease Study (ODESY). This study will undertake stratified and systematic sampling from 22,000 households (approximately 80,000 people) spread over 10 districts of the state. In addition to measuring the prevalence of blindness and visual impairment, the study will also measure individual and family demographics, health profile, food habit, nutritional status, knowledge-attitude-practice toward eye care, and the barriers/facilitators. When completed, the ODESY is expected to provide the most useful and comprehensive database on eye health status of the state.

The Sunetra has developed a gap analysis tool. It has completed analysis of one-third of the districts and is working on other districts of the state. Based on the current population of Odisha (population 42 million, 2011 census survey) ${ }^{10}$ the state should have 420 vision centers, 84 secondary centers, and 8-9 tertiary centers.

Sunetra has adopted two approaches in eye care human resource development: developing adequate allied eye health personnel, and reskilling the current professionals in the modern tools of care. The existing 200 allied health force (ophthalmic assistants) has been retrained recently. The government is introducing allied eye health courses to help ophthalmologists both in the clinic and the operating room. At the same time, the Sunetra is building a skilling center 
for all cadres of eye health professionals, including medical graduates and ophthalmologists-in-training.

The program is preparing a statewide introduction of electronic medical record system as the first step of digital eye health transition. While this will be introduced in the public sector, the private sector will be nudged to join the digital transition that will help collect and analyze the big data.

Sunetra will specifically focus on school eye health by applying most of the school screening methodology employed in the REACH program, the India Childhood Blindness Initiative of the Orbis International, ${ }^{11}$ and the model already tested in one of the districts in Odisha. ${ }^{12}$

\section{Discussion}

A population-based study measures current blindness and visual impairment. It helps in program planning. The classical research methods provide reliable estimates, but they are expensive and resource intensive. Several rapid and cost-efficient assessment tools are available to assess the crude estimate of visual impairment and blindness. ${ }^{13}$ These include Rapid Assessment Of Avoidable Blindness, Rapid Assessment Of Refractive Error, Rapid Assessment Of Visual Impairment, and Rapid Assessment Of Cataract Surgical Services. The Andhra Pradesh Eye Disease Study (1996-2000) was the first scientifically well-designed all-age population-based cross-sectional epidemiological study that was conducted in the southern state of Andhra Pradesh, India. ${ }^{14}$ This study provided several new findings such as an updated distribution on blindness and visual impairment in India, urban-rural divide (blindness: urban, 1.36\%; rural, $2.03 \%$ ), and also identified that refractive error was an important cause of avoidable blindness (second only to cataract blindness) and the foremost cause of moderate visual impairment (blindness: cataract, 44\%; uncorrected refractive error, $16.3 \%$ and moderate visual impairment: cataract, 39.9\%; uncorrected refractive error, 45.8\%). ${ }^{15,16}$ The ODESY will be a similar all-age population study and, when completed, the study would provide the most useful and comprehensive database on eye health status of the state.

The estimate of cataract surgery is considered one of the important indicators to measure the community eye care delivery. In recent years, India has done well in improving the cataract surgical rate (CSR; defined as number of cataract operations performed per million population per year; it is used as a proxy indicator of access to cataract services in a country and is usually linked to economic growth), ${ }^{17}$ cataract surgical coverage (CSC; defined as the proportion of persons and eyes with "operable" cataract who have already received surgery; it measures the impact of cataract surgery intervention programs), ${ }^{18}$ and effective cataract surgical coverage (defined as operated cataract and good outcome as a proportion of operable plus operated cataract). ${ }^{19}$ Three important factors have contributed to high CSR and good CSC rates in India (2014 data: CSR 5,050/million; CSC 66\% ${ }^{20}$ and 2016 CSR data: 5,136/million). ${ }^{2}$ These factors are follows: 1) training of ophthalmologists in modern cataract surgery using surgical microscope and insertion of intraocular lens, 2) indigenous manufacturing of high-quality affordable intraocular lenses, and 3 ) the Indian pharmaceutical industry's manufacturing of eye care medications and equipment at affordable cost. The CSR in Odisha is approximately half that seen in India (CSR 2016: India, 5,136/million; Odisha, 3,149/million), and in seven districts the CSR is less than the state average. ${ }^{2}$ Some of the important contributing factors include inadequate infrastructure and service delivery, lack of trained human resources and productivity, use of outdated technology, poor supply chain, lack of leadership, and insufficient private-public partnership. Sunetra will identify additional factors following the gap analysis.

It is generally accepted that the pyramidal eye care system provides appropriate, affordable, available, and accessible eye care to the entire demographic spread. ${ }^{21}$ This is divided by both population and function. At the bottom of the pyramid, the "Vision Center" serves a population of 50,000 people with the primary function of refractive error correction, detection of common eye diseases, and referral to the next level. At the next level, "Service Center" serves a population of 500,000 people and performs additional functions of cataract surgery, detection of emerging blinding eye diseases, such as glaucoma and diabetic retinopathy, and community-based eye care. The next higher center, the "Tertiary Center" serves a population of 5 million people and additionally functions to ensure pediatric eye care, corneal transplant, visual rehabilitation, training of eye health personnel, and clinical research. At the top of the pyramid is the "Quaternary Center" (Center of Excellence), which serves a population of 50 million people with additional functions of translational research, eye banking, innovation, advocacy, and policymaking. Based on the current population (42 million, 2011 census $)^{10}$ and assuming that the current public health system (377 community health centers, 32 district headquater hospitals, 7 medical colleges) would fit into the pyramid system, there will be a gap of 43 vision centers, 52 secondary centers, 2 tertiary centers, and additionally 1 quaternary eye center. The private not-for-profit organizations will be nudged to bridge this gap.

Adequate trained human resource is an important barrier all over the world, and Southeast Asia is no exception. ${ }^{20}$ 
The key human resources are certified allied ophthalmic personnel (AOP). The WHO recognizes the need for and benefits of AOPs. ${ }^{22}$ The International Joint Commission on Allied Health Personnel in Ophthalmology offers a variety of certificate courses in ophthalmology, ${ }^{23}$ and few medical universities in India offer some of these courses to high school graduates. ${ }^{24}$ At the conclusion of this 2-year program consisting of training and internship, the trained AOPs could independently perform an external eye examination, measure vision and intraocular pressure, perform refraction, dispense spectacles, diagnose common eye diseases for adequate referral, assist ophthalmic surgery, and participate in delivery of postoperative care. With the introduction of this course, it is hoped that adequate trained and skilled manpower would be available in a few years.

The starting point of big data acquisition and analysis is the electronic health record. The American Academy of Ophthalmology has been collecting these big data in ophthalmology since 2014. Named IRIS, Intelligent Research in Sight, it is USA's first electronic health record-based comprehensive eye disease and condition registry. ${ }^{25}$ It is a centralized data repository and reporting tool that analyzes patient data to produce easy-to-interpret national and interpractice benchmark reports and provides scientific information to improve public health. In last 3 years, as of July 1, 2017 , the registry has collected data of 37.3 million unique patients and 148 million patient visits collected from 13,199 practicing ophthalmologists. ${ }^{26}$ The IRIS is used as new eye health surveillance system that would provide population estimates of vision loss, eye diseases, eye health disparities, and barriers/facilitators to care. ${ }^{27}$ The Government of India demonstrated its intention toward standardized collection, storage, and exchange of big health data by setting up a National eHealth Authority (NeHA) in $2015 .{ }^{28}$ The vision of $\mathrm{NeHA}$ is "attainment of high-quality health services for all Indians through cost-effective and secure use of information and communication technologies in health and health-related fields." Unfortunately, significant advances have not yet been made in this regard in India. Hopefully, the digital eye health experiment will pay good dividends in the state of Odisha.

Finally, Sunetra recommends setting up an independent eye health policy and research center - the Eyehealth Planning and Innovation Center (EPIC). The main functions of the EPIC will be as follows: 1) create a strong research environment to collect and analyze big data; 2) forecast eye disease trend and ensure quality care; 3 ) periodic review and dissemination of knowledge to general public; 4) development and fostering strong complementary public-private partnership; and 5) innovation on health delivery and skill-based training of human resources. The Sunetra is an inclusive program that will include all nongovernment not-for-profit eye care providers in eye care delivery in the state. The pyramidal system of service delivery is designed to provide adequate access to eye care. The trained eye health personnel will provide comprehensive care appropriate for the level of eye care. With Government insurance and assistance, already available or recently announced,,$^{9,29}$ it is envisaged that the out-of-pocket expenses for eye care would be minimal.

\section{Conclusion}

Universal health coverage applies to eye care as much as it applies to other areas of health care. The ultimate goal of universal eye health is integration of eye health to the general health care system. With growing blurring of the margins between noncommunicable disease and eye care, it is envisaged that there will be integration of eye health into general health over a period of time. Till such time, one needs to put a focused effort for implementation of universal eye health system. The Odisha state in India has announced the political will to do so. Achieving the short-terms goals is as important as laying the foundation for long-term plans. If done well, Odisha could be the model state in India in universal eye health coverage.

\section{Author contributions}

All authors contributed toward data analysis, drafting and critically revising the paper, gave final approval of the version to be published, and agree to be accountable for all aspects of the work.

\section{Disclosure}

The authors report no conflicts of interest in this work.

\section{References}

1. World Health Organization. Universal Eye Health. A Global Action Plan 2014-2019. Geneva: World Health Organization; 2013.

2. Directorate General of Health Services, Ministry of Health \& Family Welfare, Government of India [homepage on the Internet]. New Delhi, India: Ministry of Health \& Family Welfare; 2010. Available from: www.npcb.nic.in. Accessed October 20, 2017.

3. Dandona L, Dandona R, Naduvilath TJ, et al. Is current eye-care-policy focus almost exclusively on cataract adequate to deal with blindness in India? Lancet. 1998;351(9112):1312-1316.

4. Bharath B, Krishnaiah S, Imtiaz A, Ramani RV. Prevalence and determinants of cataract surgical coverage in India: findings from a populationbased study. Int J Community Med Public Health. 2017:320-327.

5. Chandrashekhar TS, Bhat HV, Pai RP, Nair SK. Coverage, utilization and barriers to cataract surgical services in rural South India: results from a population-based study. Public Health. 2007;121(2):130-136.

6. Planning Commission of India. High-level expert group report on Universal Health Coverage for India. New Delhi, India; 2011. Available from: planningcommission.nic.in/reports/genrep/rep_uhc0812.pdf

7. National Health Mission [homepage on the Internet]. New Delhi, India: National Health Mission. Available from: www.nhm.gov.in. Accessed October 20, 2017. 
8. Dandona L. Blindness control in India: beyond anachronism. Lancet. 2000;356 Suppl:s25.

9. uehpodisha.in [homepage on the Internet] Universal Eye Health programme, Odisha. Department of Health \& Family Welfare, Govt, of Odisha; 2018. Available from: http://uehpodisha.in/frmhomenew.aspx. Accessed July 1, 2018.

10. IndianPopulation2017. Population of Odisha 2017; 2017. Available from: indiapopulation2017.in/population-of-odisha-2017.html. Accessed October 20, 2017.

11. Orbis International. Where we work. Asia. Available from: https:// www.orbis.org/en/where-we-work. Accessed July 1, 2018.

12. Panda L, das T, Nayak S, et al. Tribal Odisha Eye Disease Study. TOES \# 2. Rayagada School Screening Program-Effectiveness of multistage screening and accuracy of school teachers in vision screening and other ocular anomalies detection. Clinical Ophthalmol. 2018; 12:1181-1187

13. Marmamula S, Keeffe JE, Rao GN. Rapid assessment methods in eye care: an overview. Indian J Ophthalmol. 2012;60(5):416-422.

14. Dandona R, Dandona L, Naduvilath TJ, Nanda A, Mccarty CA. Design of a population-based study of visual impairment in India: The Andhra Pradesh Eye Disease Study. Indian J Ophthalmol. 1997;45(4): 251-257.

15. Dandona R, Dandona L. Review of findings of the Andhra Pradesh Eye Disease Study: policy implications for eye-care services. Indian J Ophthalmol. 2001;49(4):215-234.

16. Dandona R, Dandona L, Srinivas M, et al. Moderate visual impairment in India: the Andhra Pradesh Eye Disease Study. Br J Ophthalmol. 2002;86(4):373-377.

17. Wang W, Yan W, Fotis K, et al. Cataract surgical rate and socioeconomics a global study. Invest Ophthalmol Vis Sci. 2016;57(14):5872-5881.

18. Limburg H, Foster A. Cataract Surgical Coverage: An indicator to measure the impact of cataract intervention programmes. Community Eye Health. 1998;11(25):3-6.

19. Ramke J, Gilbert CE, Lee AC, Ackland P, Limburg H, Foster A. Effective cataract surgical coverage: An indicator for measuring quality-ofcare in the context of Universal Health Coverage. PLoS One. 2017;12(3): e0 172342 .
20. Das T, Ackland P, Correia M, et al. Is the 2015 eye care service delivery profile in Southeast Asia closer to universal eye health need! Int Ophthalmol. 2018;38(2):469-480.

21. Rao GN, Khanna RC, Athota SM, Rajshekar V, Rani PK. Integrated model of primary and secondary eye care for underserved rural areas: the L V Prasad Eye Institute experience. Indian J Ophthalmol. 2012; 60(5):396-400.

22. World Health Organization. Mid Level Ophthalmic Personnel in South East Asia. South East Asia Region and New Delhi: World Health Organization; 2002;2002:1-35.

23. JCAHPO [homepage on the Internet]. St. Paul, MN: JCAHPO. Available from: www.jcahpo.org. Accessed November 12, 2017.

24. tnmgrmu.ac.in [hmepage on the Internet] The Tamil Nadu Dr.M.G.R Medical University; 2016. Available from: https://www.tnmgrmu. ac.in/index.php/results/results-allied-health-sciences.html. Accessed November 12, 2017.

25. American Academy of Ophthalmology. IRIS ${ }^{\circledR}$ Registry. San Francisco, CA, USA: American Academy of Ophthalmology. Available from: https://www.aao.org/iris-registry. Accessed November 11, 2017.

26. Parke DW, Rich WL, Sommer A, Lum F. The American Academy of Ophthalmology's IRIS ${ }^{\circledR}$ Registry (Intelligent Research in Sight Clinical Data): A Look Back and a Look to the Future. Ophthalmology. 2017; 124(11):1572-1574.

27. Coleman AL. How Big Data Informs Us About Cataract Surgery: The LXXII Edward Jackson Memorial Lecture. Am J Ophthalmol. 2015;160(6):1091-1103.

28. National Health Portal. National eHealth Authority (NeHA). Available from: https://nhp.gov.in/national_eHealth_authority_neha_mtl. Accessed May 29, 2017.

29. health.odisha.gov.in [homepage on the Internet] department of Health and Family Welfare. Government of Odisha; 2018. Available from: https://health.odisha.gov.in. Accessed September 6, 2018.
Clinical Ophthalmology

\section{Publish your work in this journal}

Clinical Ophthalmology is an international, peer-reviewed journal covering all subspecialties within ophthalmology. Key topics include: Optometry; Visual science; Pharmacology and drug therapy in eye diseases; Basic Sciences; Primary and Secondary eye care; Patient Safety and Quality of Care Improvements. This journal is indexed on Submit your manuscript here: http://www.dovepress.com/clinical-ophthalmology-journal

\section{Dovepress}

PubMed Central and CAS, and is the official journal of The Society of Clinical Ophthalmology (SCO). The manuscript management system is completely online and includes a very quick and fair peer-review system, which is all easy to use. Visit http://www.dovepress.com/ testimonials.php to read real quotes from published authors. 